\title{
Lipoprotein (a) levels, apolipoprotein (a) phenotypes and thyroid autoimmunity
}

\author{
Eleni T Bairaktari ${ }^{1}$, Alexandros D Tselepis ${ }^{2}$, Haralampos J Millionis and Moses S Elisaf \\ Department of Internal M edicine, M edical School, and ${ }^{2}$ Laboratory of Biochemistry, Department of Chemistry, University of Ioannina, Ioannina, \\ Greece, and ${ }^{1}$ Biochemistry Laboratory, U niversity Hospital, Ioannina, Greece
}

(Correspondence should be addressed to M S Elisaf, Department of Internal M edicine, M edical School, U niversity of Ioannina, GR 45110 Ioannina, Greece)

\begin{abstract}
It has been reported that euthyroid normolipidemic males and postmenopausal females exhibit significantly higher serum lipoprotein (a) (Lp(a)) levels compared with age- and sex-matched normolipidemic controls. However, it is well known that there is an inverse correlation between $\mathrm{Lp}(\mathrm{a})$ concentration and apolipoprotein (a) (apo(a)) isoform size. Thus, it is imperative to exclude differences in apo(a) isoform frequencies between subjects with or without thyroid autoimmunity in order to verify if there is an association between thyroid autoimmunity and increased Lp(a) concentration. To exclude such an effect of different apo(a) isoform frequencies, we determined apo(a) phenotypes in 22 patients ( 9 males and 13 postmenopausal females) with thyroid autoimmunity and in 64 ( 29 males and 35 females) age- and sex-matched individuals without thyroid autoimmunity (control group). There were no significant differences in the values of lipid parameters between the two groups, including $L p(a)$. We did not detect any significant differences in the apo(a) phenotype frequencies between the two groups. Additionally, in neither of the subgroups formed according to the presence of low molecular vs high molecular weight apo(a) isoforms were there any significant differences in median serum Lp(a) levels between patients with and without thyroid autoimmunity. Thus, our results contradict the previously reported association between thyroid autoimmunity and Lp(a) concentrations.
\end{abstract}

European Journal of Endocrinology 140 474-476

\section{Introduction}

Lipoprotein (a) (Lp(a)) is a low density lipoprotein (LDL)like particle in which apolipoprotein (a) (apo(a)) is linked to apoB100 by a disulfide bridge (1). Several studies have pointed out that high Lp(a) levels are associated with atherosclerotic disease, including myocardial infarction (2-4). Lp(a) concentrations may be altered by various environmental or hormonal factors as well as pathological situations (5-7). It has recently been reported that euthyroid males and postmenopausal females with thyroid autoimmunity present with increased serum $L p(a)$ levels, implying a role of thyroid autoimmunity in the Lp(a) metabolism (8). It should be mentioned, however, that the apolipoprotein (a) gene locus on chromosome 6q 2.6-2.7 is the major gene controlling $L p(a)$ serum concentrations $(9,10)$. Six different isoforms (designated $\mathrm{F}, \mathrm{B}, \mathrm{S}_{1}, \mathrm{~S}_{2}, \mathrm{~S}_{3}, \mathrm{~S}_{4}$ according to different electrophoretic mobilities) that vary in size from $\sim 400 \mathrm{kDa}$ to $>800 \mathrm{kDa}$ were originally described. In the general population the size of these isoforms is inversely related to serum concentrations of
Lp(a). That is, individuals with low molecular weight (LMW) isoforms ( $F, B, S_{1}$ and $S_{2}$ ) have, on average, high Lp(a) concentrations, whereas those with high molecular weight (HMW) isoforms $\left(\mathrm{S}_{3}, \mathrm{~S}_{4}\right)$ express low Lp(a) serum concentrations $(9-11)$. Thus, it is necessary to exclude differences in apo(a) isoform frequencies between subjects with or without thyroid autoimmunity in order to verify if there is an association between thyroid autoimmunity and increased serum $L p(a)$ concentration.

We undertook the present study to examine the correlation of thyroid autoimmunity with lipoprotein (a) concentration and apolipoprotein (a) phenotypes.

\section{Materials and methods}

We studied 22 subjects (9 males and 13 postmenopausal females) aged 31-52 years with thyroid autoimmunity (increased titers of thyroperoxidase and/or thyroglobulin antibodies) as well as 64 subjects (29 males and 35 females) aged 30-51 years without 
thyroid autoimmunity (control group), selected from individuals receiving medical check-up at our hospital free from any illness by history, physical examination, and routine laboratory data. Patients and controls with a known family history of primary hyperlipidemia, excessive alcohol consumption, diabetes mellitus, obesity (body mass index $>30 \mathrm{~kg} / \mathrm{m}^{2}$ ), liver disease, and systemic illnesses were excluded from the study. Furthermore, in all individuals thyroid function tests were within normal limits.

In patients and controls blood samples were taken after a 14-h overnight fast for the determination of lipid parameters, thyroid function tests (total and free thyroxine $\left(T_{4}\right)$, total tri-iodothyronine $\left(T_{3}\right)$, and thyrotropin), and thyroid autoantibodies (thyroperoxidase and thyroglobulin antibodies). The measurement of serum lipid parameters was performed by standard commercially available techniques as previously described (12). $L p(a)$ was measured using a monoclonal anti-Lp(a) antibody technique by the enzyme immunoassay Macra Lp(a) (Terumo Medical Corporation Diagnostic Division, Elkton, MD, USA). The lower limit of detectability was $0.8 \mathrm{mg} / \mathrm{dl}$. In cases of Lp(a) levels less than $0.8 \mathrm{mg} / \mathrm{dl}$, the value of $0.8 \mathrm{mg} / \mathrm{dl}$ was used for statistical reasons. The intra-assay and the interassay coefficients of variation were less than $6 \%$ and $10.3 \%$ respectively. In a recent report using this monoclonal antibody no cross reactivity with plasminogen, $L D L$, very low density lipoprotein (VLDL), or high density lipoprotein (HDL) was observed (13). Thyroid function tests were measured by immunoassay on an AXSYM analyzer (A bbott Laboratory, A bbott Park, IL, USA). Antiperoxidase and thyroglobulin antibodies were detected by hemagglutination. Positive samples were regarded as those which provided agglutination to a dilution of at least 1/400 and $1 / 640$ respectively.

A po(a) isoform size was then determined by agarose gel electrophoresis followed by immunoblotting as described previously (12). A standard solution (Immuno-France, S.A.R.L., Rungis, France) containing six different isoforms corresponding to the $F, B, S_{1}, S_{2}, S_{3}, S_{4}$ isoforms in the nomenclature of Utermann et al. (11) was used in order to characterize our samples.

\section{Statistical analysis}

Lipoprotein (a) values were expressed in terms of median and range. A comparison of continuous variables was performed by an unpaired two tailed Student's t-test. Because of the highly skewed distribution of $L p(a)$ the non parametric Mann-Whitney $U$ test was applied to discriminate for differences in $L p(a)$ levels between groups. Pearson's $\chi^{2}$ test was applied to compare frequencies between groups. The LMW group includes all subjects with at least one of the isoforms $F$, $B, S_{1}$, or $S_{2}$, while the HMW group comprised all subjects with only $S_{3}$ or $S_{4}$ isoforms or with null type. Significance levels were set at $P<0.05$ in all cases.

\section{Results}

There were no significant differences in the values of lipid parameters between the two groups, including Lp(a) $(8.6 \mathrm{mg} / \mathrm{dl} \quad(0.8-84 \mathrm{mg} / \mathrm{dl})$ vs $9.4 \mathrm{mg} / \mathrm{dl} \quad(0.8-$ $108 \mathrm{mg} / \mathrm{dl}$ ), $\mathrm{P}=$ not significant). We did not detect any significant differences in the apo(a) phenotype frequencies between the two groups (Table 1). Therefore, the absence of difference in serum $L p(a)$ concentration is a true finding and not biased by apo(a) type frequency differences. Additionally, in neither of the subgroups formed according to the presence of low molecular weight vs high molecular weight apo(a) isoforms were there any significant differences in median serum $L p(a)$ levels between patients with and without thyroid autoimmunity (Table 1).

\section{Discussion}

In our study no association was found between thyroid autoimmunity and increased serum Lp(a) concentration when apo(a) phenotypes were taken into account. In other words, our results do not seem to confirm previously published data which showed an association between thyroid autoimmunity and increased Lp(a) levels in normolipidemic healthy individuals (males and postmenopausal females) (8). Since the $L p(a)$ concentration has been shown to be elevated in inflammatory

Table 1 Distribution of apo(a) phenotypes and Lp(a) concentrations in the study population.

\begin{tabular}{|c|c|c|c|c|c|c|}
\hline \multirow[b]{2}{*}{ Phenotype } & \multicolumn{3}{|c|}{$\begin{array}{l}\text { Patients with thyroid autoimmunity } \\
\qquad(n=22)\end{array}$} & \multicolumn{3}{|c|}{$\begin{array}{l}\text { Patients without thyroid autoimmunity } \\
\qquad(n=64)\end{array}$} \\
\hline & $\begin{array}{l}\text { Number } \\
\text { of patients }\end{array}$ & $\%$ & $\begin{array}{l}\text { Median value } \\
\text { (range) } \\
\mathrm{mg} / \mathrm{dl}\end{array}$ & $\begin{array}{l}\text { Number of } \\
\text { patients }\end{array}$ & $\%$ & $\begin{array}{c}\text { Median value } \\
\text { (range) } \\
\text { mg/dl }\end{array}$ \\
\hline $\begin{array}{l}\mathrm{HMW}^{\mathrm{a}} \\
\mathrm{LMW}^{\mathrm{b}}\end{array}$ & $\begin{array}{r}15 \\
7\end{array}$ & $\begin{array}{l}68.2 \\
31.8\end{array}$ & $\begin{array}{r}4(0.8-28) \\
20(0.8-84)\end{array}$ & $\begin{array}{l}45 \\
19\end{array}$ & $\begin{array}{l}70.3 \\
29.7\end{array}$ & $\begin{array}{r}4.5(0.8-32) \\
22(0.8-108)\end{array}$ \\
\hline
\end{tabular}

${ }^{a} \mathrm{HMW}$, high molecular weight. All subjects with only $\mathrm{S}_{3}$ or $\mathrm{S}_{4}$ isoforms or with null type; ${ }^{b} \mathrm{LMW}$, low molecular weight. All subjects with either of the isoforms $F, B, S_{1}$ or $S_{2}$. 
or immune processes and the role of an inflammatory process in the atherosclerotic plaque formation and rupture is prominent, the authors proposed that an autoimmune process, triggered for example by a concomitant intracellular infection, may occur in patients with high Lp(a) levels $(8,14)$.

The reasons for the observed discrepancies are not entirely clear-cut but may be related to the selection of patients (Lotz and Salabe (8) selected normolipidemic subjects and patients, while in our cohort the study population was randomly selected), to ethnic differences or to other poorly understood factors. However, thelack of apo(a) phenotypes in the study of Lotz and Salabe make their results problematic (8). Further studies with an adequate number of individuals of different ethnic backgrounds, including additional markers of autoimmunity are needed further to clarify this interesting issue.

\section{References}

1 Berg K. A new serum type system in man. The Lp system. Acta Pathologica M icrobiologica Scandinavica 196359 369-382.

2 Rader DJ \& Brewer HB. Lipoprotein (a). Clinical approach to a unique atherogenic lipoprotein. Journal of the American M edical Association 1992267 1109-1112.

3 Shaefer EJ, Lamon-Fava S, Jenner JL, MCNamara JR, Ordovas JM, Davis CE et al. Lipoprotein (a) levels and risk of coronary heart disease in men. The Lipid Research Clinics Coronary Primary Prevention Trial. Journal of the American M edical Association 1994 271 999-1003.

4 Dahlen GH, Guyton JR, A ttar M, Farmer JA, Kautz JA \& Gotto AM $J r$. Association of levels of lipoprotein $L p(a)$, plasma lipids, and other lipoproteins with coronary artery disease documented by angiography. Circulation 198674 758-765.

5 Hong $\mathrm{Y}$, Dhalen GH, Pedersen N, Heller DA, McClearn CE \& deFaire U. Potential environmental effects on adult lipoprotein (a) levels: results from Swedish twins. Atherosclerosis 1995117295 304.

6 Milionis HJ, Elisaf MS, Tselepis A, Bairaktari E, Karabina S-A \& Siamopoulos KC. A polipoprotein (a) phenotypes and lipoprotein (a) concentrations in patients with renal failure. American Journal of Kidney Diseases 1999 (In Press).

7 Paoli M, Bellabarba G, Velazquez E, Mendoza S, Molina C, Wang P et al. Sex steroids, lipids, and lipoprotein cholesterols in women with subclinical and overt hypothyroidism before and after L-thyroxine therapy. Clinica Chimica Acta 1998275 81-91.

8 Lotz H \& Salabe GB. Lipoprotein (a) increase associated with thyroid autoimmunity. European Journal of Endocrinology 1997 $13687-91$.

9 Boerwinkel E, Leffert CC, Lin J, Lackner C, Chiesa G \& Hobbs HH. A polipoprotein (a) gene accounts for greater than $90 \%$ of the variation in plasma lipoprotein (a) concentrations. Journal of Clinical Investigation $19929052-60$.

10 Austin MA, Sandholzer C, Selby JV, Newman B, Krauss RM \& Utermann G. Lipoprotein (a) in women twins: heritability and relationship to apolipoprotein (a) phenotypes. American Journal of Human Genetics 199251 829-840.

11 Utermann G, Menzel HJ, Kraft HG, Duba HC, Kemmler HG \& Seitz C. $L p(a)$ glycoprotein phenotypes, inheritance and relation to Lp(a) lipoprotein concentration in plasma. Journal of Clinical Investigation $198780458-465$.

12 Karabina S-AP, Elisaf M, Goudevenos J, Siamopoulos KC, Sideris D $\&$ Tselepis A. PAF-acetylhydrolase activity on $L p(a)$ before and after $\mathrm{Cu}^{2+}$-induced oxidative modification in vitro. Atherosclerosis $1996125121-134$

13 Silberman SR, Armentrout MA, Vella FA \& Saha AL. MACRA ${ }^{\mathrm{TM}}$ $L p(a)$ for quantitation of human lipoprotein (a) by enzyme linked immunoassay. Clinical Chemistry 199036961 (Abstract).

14 Dahlen G, Boman J, Birgander LS \& Lindbolm B. Lp(a) lipoprotein, IgG, IgA and IgM antibodies to chlamydia pneumoniae and HLA class II genotype in early coronary artery disease. Atherosclerosis 1995114 165-174.

Received 8 January 1999

Accepted 21 January 1999 